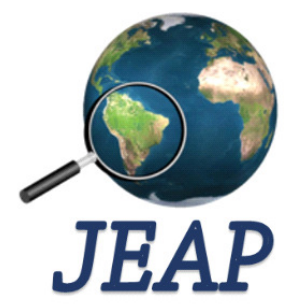

ISSN: 2525-815X
Journal of Environmental Analysis and Progress

Journal homepage: www.ufrpe.br/jeap

http://dx.doi.org/10.24221/jeap.2.3.2017.1340.177-185

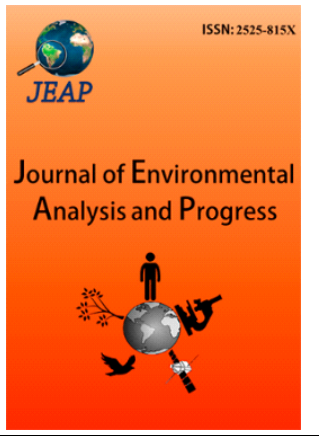

\title{
Variabilidade no regime pluvial em duas mesorregiõres da Paraíba e sua relação com o fenômeno EL Niño Oscilação Sul
}

\section{Variability in rainfall patterns in two mesoregions of Paraiba and its relationship with the El Niño Southern Oscillation phenomenon}

\author{
Hermes Alves de Almeida ${ }^{\mathrm{a}}$, Everton de Araújo Medeiros ${ }^{\mathrm{b}}$ \\ a Universidade Estadual da Paraíba-UEPB, Departamento de Geografia, Rua Baraúnas, n. 351, Bairro Universitário, \\ Campina Grande-PB. CEP: 58429-500. E-mail: hermes_almeida@uol.com.br. \\ ${ }^{\mathrm{b}}$ UEPB, Bolsista CNPq. E-mail: evertonaraujo401@gmail.com.
}

\section{A R T I C L E I N F O \\ Recebido 16 Mai 2017}

Aceito 01 Jul 2017

Publicado 31 Jul 2017

\section{A B S T R A C T}

The El Niño Southern Oscillation (ENSO) is always associated with the occurrence of rain and drought. The study aimed to determine the possible association in the annual variability of the rainfall regime in the Sergão and Borborema regions of Paraíba. It was used the monthly rainfall series, the 1961-2015 periods, assigned by the Executive Agency for the Management of the State of Paraíba Waters (EFSA), these geographical clippings. The rainfall data were analyzed by statistical climatologically criteria, the monthly rainfall regimes, and the annual rainy season is established for each site and the mesoregions. Rainfall totals were selected observed in the years of the occurrence of ENSO strong and weak intensities and neutral, being calculated the deviations from the median and compared with the standard deviation of the series. The main results indicated that the monthly rainfall patterns and the annual rainy season are irregular, asymmetric and therefore it is recommended to use the median. The short rainy season concentrates from January to April, and it rains more than half the year, with no rain possibility. In the years of El Niño and La Niña strong intensity there is a tendency to rain below and above the expected, although the observed deviations are smaller, on average than the standard deviation of the series. In the ENSO weak there is a tendency for more rain in the El Niño and not almost decrease in La Niña. Neutral years come to rain even less than in El Niño of strong intensity.

Keywords: El Niño, La Niña, rainfall, drought.

\section{R E S U M O}

O El Niño Oscilação Sul (ENOS) é sempre associado a ocorrência de chuva e/ou de seca. O estudo objetivou avaliar a existência de associação na variabilidade anual do regime pluvial nas mesorregiões paraibanas do Sertão e Borborema. Foram utilizadas séries de chuvas mensais, do período de 1961-2015, cedidas pela Agência Executiva de Gestão das Águas do Estado da Paraíba (AESA), desses recortes geográficos. Os dados de precipitação pluvial foram analisados mediante critérios da estatística climatológica, sendo estabelecidos os regimes pluviais mensal, anual e o da estação chuvosa, para cada local e para as mesorregiões. Foram selecionados os totais de chuvas observados, nos anos de ocorrência do ENOS de intensidades forte e fraca e nos neutros, calculados os desvios em relação à mediana e comparados com o desvio padrão da série. Os principais resultados indicaram que os regimes pluviais mensais, anual e o da estação chuvosa são irregulares, assimétricos e, portanto, recomenda-se o uso da mediana. A curta estação chuvosa concentra-se de janeiro a abril e chove mais da metade do previsto anual, com possibilidade de não chover. Nos anos de El Niño e La Niña de intensidades fortes há tendência de chover abaixo e acima do esperado, embora os desvios observados sejam menores, em média, que o desvio padrão da série. Em ENOS fraco há uma tendência de chover mais nos de El Niño e não a quase 
redução nos de La Niña. Em anos neutros chega a chover até menos que nos de El Niño de intensidade forte.

Palavras-Chave: El Niño, La Niña, chuva, seca.

Introdução

O regime de chuvas no semiárido nordestino é caracterizado pela elevada irregularidade espacial e temporal, sendo comum chover torrencialmente num local e nada na sua circunvizinhança. Essas características são típicas do regime pluvial de cada microrregião do Estado da Paraíba. Além disso, a curta estação chuvosa ocorre de forma diferenciada em quantidade, distribuição e duração (Almeida \& Farias, 2015).

Há vários fatores que pode contribuir para aumentar, ainda mais, a variabilidade interanual da chuva no semiárido nordestino, dentre esses, cita-se o fenômeno El Niño Oscilação Sul (ENOS). Esse fenômeno oceânico e atmosférico é caracterizado pela anomalia da temperatura das águas superficiais do Oceano Pacífico tropical, nas regiões denominadas de El Niño $3\left(5^{\circ} \mathrm{N}-5^{\circ} \mathrm{S}\right.$, $\left.150^{\circ}-90^{\circ} \mathrm{W}\right)$ e $4\left(5^{\circ} \mathrm{N}-5^{\circ} \mathrm{S}, 160^{\circ}-150^{\circ} \mathrm{W}\right)$.

A ocorrência desse fenômeno oceânico é registrada pela diferença entre a temperatura das águas superficiais do pacífico observada e a média da série. Quando essa desigualdade for maior que $0,5^{\circ} \mathrm{C}$ (EL Niño) e menor que $-0,5^{\circ} \mathrm{C}$, de La Niña (Trenberth, 1997).

O ENOS representa uma combinação entre o oceano e atmosfera, cuja influência se dá em larga escala, podendo influenciar a circulação geral da atmosfera e, consequentemente, as condições de tempo em diversas regiões do Brasil e do mundo (Berlato \& Fontana, 2003). Embora não seja um fenômeno cíclico, dura, em média, de seis a dezoito meses, inicia, geralmente, no meado do ano, atinge a máxima intensidade no mês de dezembro e termina na metade do ano seguinte (Almeida, 2002).

Desde o meado do século passado, vários pesquisados têm se interessado em relacionar as oscilações nas condições do tempo às ocorrências do fenômeno ENOS, especialmente, a variabilidade espacial e temporal das chuvas. Os impactos globais, associados a esse fenômeno, ocorrem de forma diferenciada tanto no regime de chuva e/ou de secas quanto no de temperatura.

O semiárido nordestino por ser uma região historicamente mais afetada por grandes e continuas seca, desde o século XVI, há sempre uma preocupação de estudar a oscilação da chuva com a ocorrência do fenômeno EL Niño Oscilação Sul. Nos estudos realizados por Kane (1989), utilizando-se uma série de 137 anos (1849 a 1985), encontrou que, dos 29 anos de existência de El Niños, apenas 12 (41,37\%) coincidiram com os anos de seca.

Mesmo que exista uma crença popular que nos anos de El Niño chovam menos e nos de La Niña mais, esses extremos podem ocorre independentes da presença ou não desse fenômeno. Essa resposta pode ser diferenciada, por que a chuva é influenciada por outros sistemas atmosféricos e/ou pela combinação das condições oceânicas do atlântico tropical (Alves \& Repelli, 1992).

Molion \& Bernardo (2002) citam que o impacto causado pelos ENOS pode ser sentido, principalmente, pela modificação no regime pluvial e a depender da intensidade do evento, pode resultar em secas severas e interferir, de forma expressiva, nas atividades humanas.

Segundo Souza, Alves \& Nobre (1998), as condições do atlântico tropical também influenciam o regime pluvial, na região nordeste, tanto nos meses da pré-estação quanto nos da estação chuvosa. Eles citaram que, nos anos que coincidem com a fase positiva do dipolo do atlântico, a chuva ficou abaixo da média no setor norte e leste do Nordeste.

Neste contexto, os mecanismos que afetam o regime pluvial no nordeste brasileiro podem estar relacionados às anomalias na temperatura da água dos Oceanos Pacífico e Atlântico Tropical. Assim, a intensidade do ENOS, associada com as do dipolo do atlântico é importante para modular o regime pluvial nessa região e no semiárido (Andreoli \& Kayano, 2007; Mendonça \& Danni-Oliveira, 2007).

Considerando uma possível relação da variabilidade anual da chuva nas mesorregiões paraibana do Sertão e Borborema com as fases extremas do El Niño Oscilação Sul, houve a necessidade de estabelecer o regime pluvial e associá-lo com as intensidades forte e fraca das chuvas.

\section{Material e Métodos}

Neste estudo foram utilizadas séries mensais e anuais de precipitação pluvial referentes ao período de 1961-2015, das mesorregiões do sertão da Paraíba: Princesa Isabel $\left(07^{\circ} 44^{\prime} 12^{\prime}\right.$ 'S e 37 $\left.59^{\prime} 36^{\prime \prime} \mathrm{W}\right), \quad$ Teixeira $\quad\left(07^{\circ} 13^{\prime} 22^{\prime}\right.$ 's e $\left.37^{\circ} 15^{\prime} 15^{\prime}, \mathrm{W}\right), \quad$ Cajazeiras $\quad\left(06^{\circ} 53^{\prime} 25^{\prime}, \mathrm{S}\right.$ e 38 $33^{\prime} 19^{\prime}, \mathrm{W}$ ) e do Cariri (Monteiro $07^{\circ} 29^{\prime} 20^{\prime}, \mathrm{S}$ e $\left.36^{\circ} 17^{\prime} 14^{\prime}, \mathrm{W}\right)$, como mostra a Figura 1. 


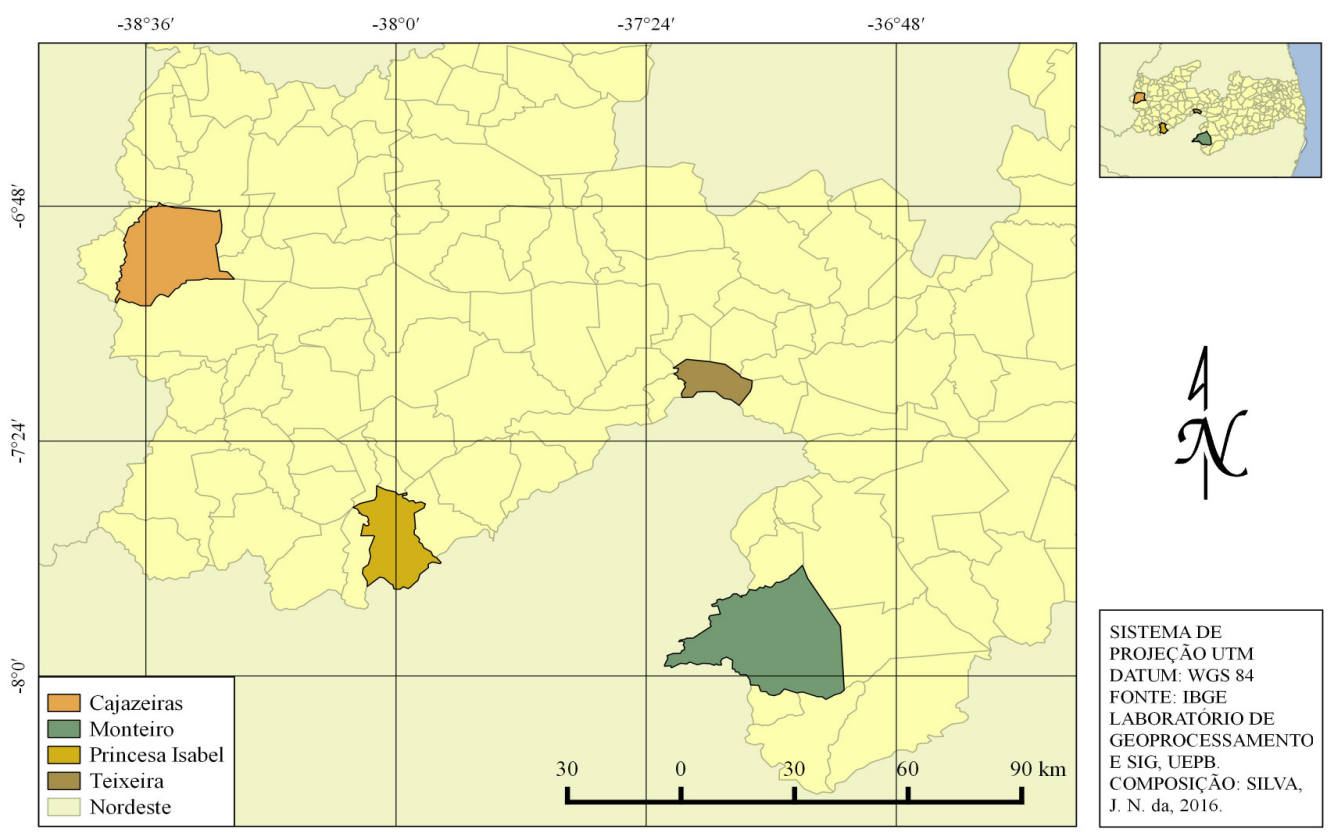

Figura 1. Mapa geográfico do estado da Paraíba, com destaque para as mesorregiões do Sertão e Borborema

Os dados mensais e anuais de chuvas das referidas localidades foram cedidos pela Agência Executiva de Gestão da Águas do Estado da Paraíba, AESA, em Campina Grande.

O agrupamento mensal e anual dos referidos dados foi feito obedecendo à sequência cronológica, sendo determinadas as medidas de tendência central (média e mediana), de dispersão (desvio padrão) e os parâmetros da distribuição de frequência. Maiores detalhes de procedimentos metodológicos, encontra-se no artigo de Almeida $\&$ Farias (2015).

Após análises gráficas das médias mensais e anuais- das médias e medianas- da precipitação pluvial, constatou-se, que os valores das médias diferiam dos respectivos valores medianos. Por isso, os modelos de distribuição são assimétricos e, portanto, a medida de tendência central adotada foi a mediana e não a média.

Para averiguar se existe ou não influência do El Niño e La Niña nos anos normais (sem ENOS), comparou-se o total anual de chuva observado no ano de El Niño, La Nina ou neutro com o respectivo valor mediano da série.

O desvio relativo observado (Dr) da chuva, ou anomalia, para os anos de El Niño, La Niña e neutro foram determinados pela diferença entre o total de chuva observado (em cada situação) e a mediana da série, expressas em milímetros e em percentagem, calculados pelas Equações 1 e 2.

$$
\begin{aligned}
& \operatorname{Dr}(\mathrm{mm})=\text { total de chuva observado }(\mathrm{mm})-\text { mediana }(\mathrm{mm}) \\
& \operatorname{Dr}(\%)=\frac{\text { total de chuva observado }(\mathrm{mm})-\text { mediana }(\mathrm{mm})}{\text { mediana }(\mathrm{mm})} \times 100
\end{aligned}
$$

As análises foram feitas separadamente em função da intensidade do El Niño e da La Niña (forte e fraco). $\mathrm{O}$ mesmo procedimento foi utilizado para os anos neutros (sem ocorrência do El Niño e/ou da La Niña).

De posse do valor anual da chuva, para cada uma das três situações descritas, calcularamse os desvios relativos observados e em seguida comparados com o desvio padrão (DP) da média da série. Como o DP é um indicador dos desvios positivo e negativo da média, o critério adotado foi o de considerar a contribuição negativa do valor do DP para os anos de El Niño e a positiva para os de La Niña. Considerando os anos neutros, adotaram-se os dois valores do DP.

Esses critérios permitiram comparar se o desvio relativo da chuva (observado), nos anos de ENOS ou na ausência deles, foram maiores ou menores que o valor do DP da média (da série), ou seja, o esperado.

Os cálculos, análises estatísticas, bem como a confecção dos gráficos e quadros foram feitos utilizando-se a planilhas Excel. 


\section{Resultados}

As médias mensais das medias, medianas e desvios padrão da média (DP) da precipitação

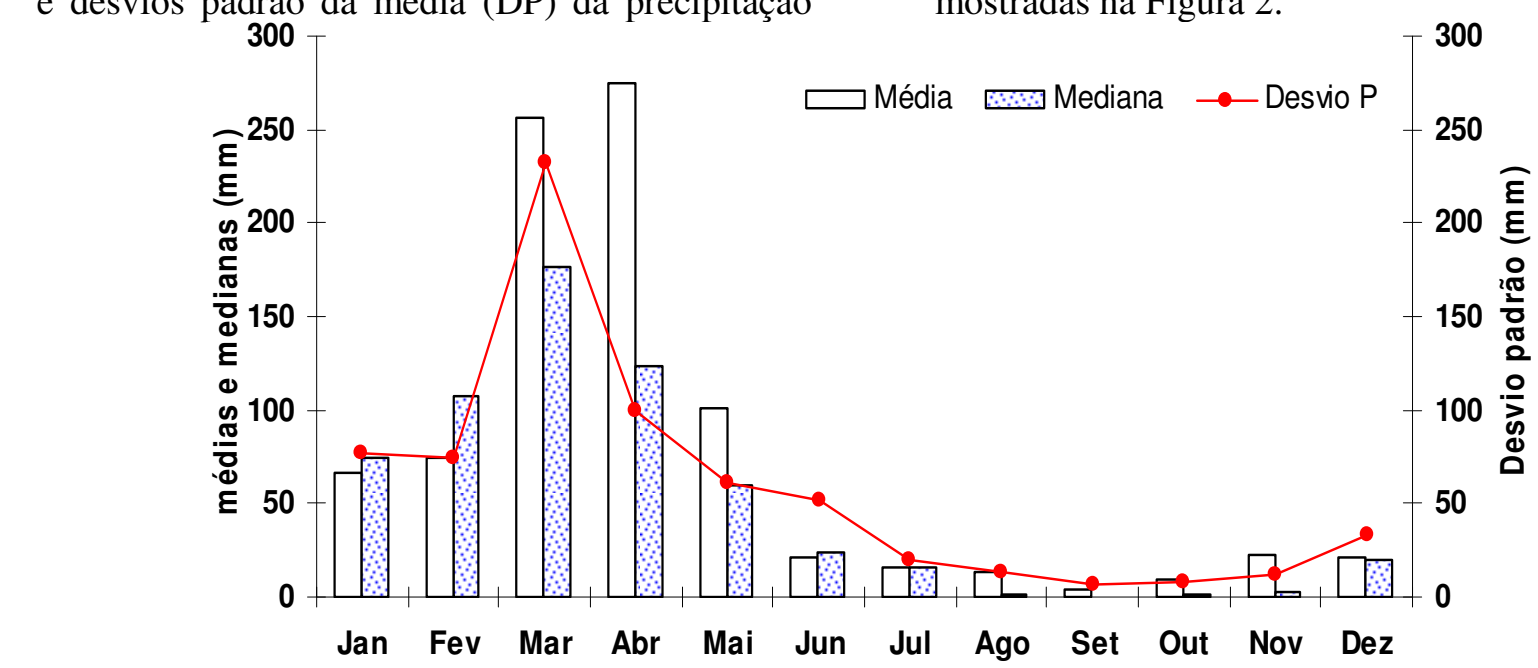

pluvial, para as três localidades da mesorregião do sertão da Paraíba e uma da do Cariri são mostradas na Figura 2.

Figura 2. Médias mensais da média, mediana e desvio padrão da precipitação pluvial. Médias das mesorregiões paraibana do Sertão e Borborema.

Observa-se que, os valores das médias mensais da chuva são extremamente irregulares ao longo do ano, cujos desvios padrão médio superam as médias aritméticas, nos meses de junho a fevereiro.

Os valores dos desvios padrão da média são superiores aos das médias nos meses de julho a fevereiro-março. Até mesmo nos meses mais chuvosos, há uma elevada variabilidade.

Analisando-se a distribuição mensal (Figura 2) verifica-se que as médias mensais das médias são diferentes e superiores às medianas. Isso indica, portanto, que o modelo de distribuição é assimétrico e o coeficiente de assimetria de Person é positivo. Portanto, a média aritmética, mesmo sendo a medida de tendência central mais usada, não é o valor mais provável de ocorrer.

Devido à condição de assimetria mensal, a curta estação chuvosa é representada pela sequência dos maiores valores medianos (Figura $3)$.

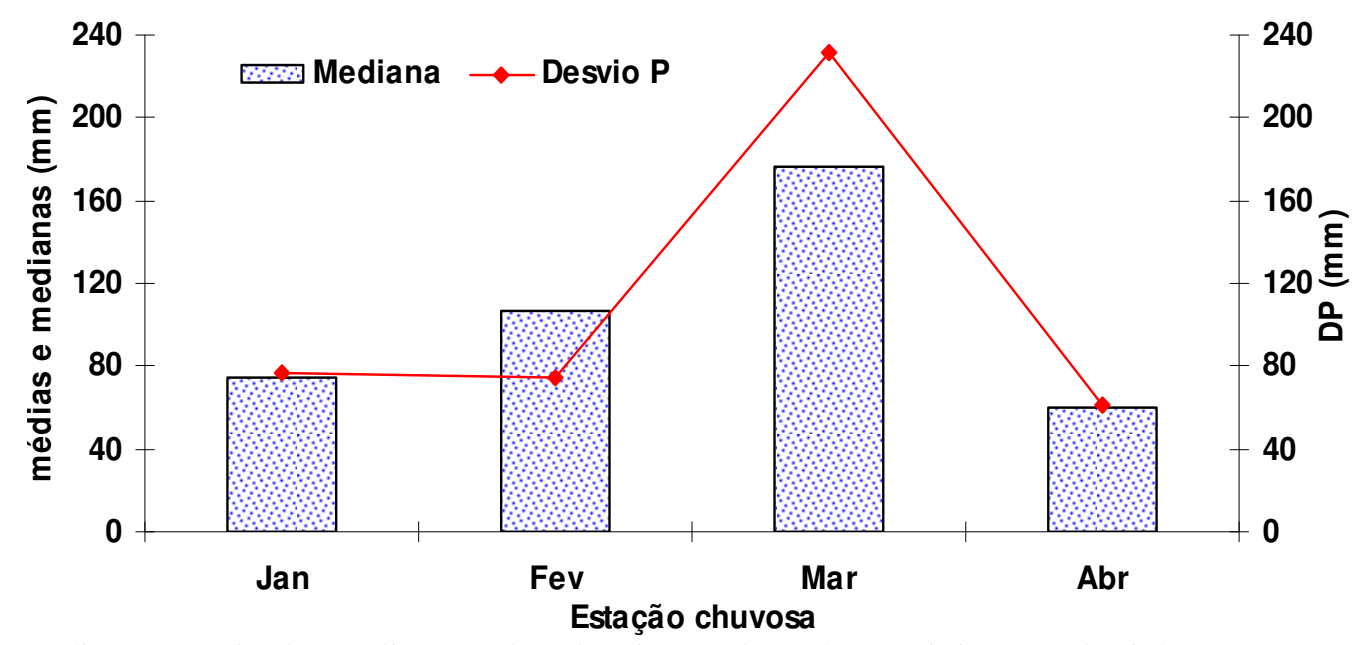

Figura 3. Médias mensais da mediana e dos desvios padrão da precipitação pluvial, nos meses da estação chuvosa. Médias das mesorregiões paraibana do Sertão e Borborema.

Ao comparar as medianas dos meses da estação chuvosa com os respectivos DPs (Figura 3), observa-se que há uma elevada irregularidade na distribuição pluvial, mesmo nessa época, cujas dispersões ultrapassam as medianas esperadas, em três dos quatros meses. Isso indica, portanto, que até mesmo na curta época de chuva, pode não chover, inclusive no mês mais chuvoso (março), porque o desvio padrão supera a média.

Quando se compara a distribuição de chuvas de um local com outro ou na mesorregião, verifica-se que difere em quantidade, duração e distribuição. Mesmo assim, nesse curto período, chove o equivalente a $56,0 \%$ do total anual. 
Destaca-se, ainda, que totais mensais de chuvas inferiores às médias esperadas, ocorreram com frequências de 63,$0 ; 55,4 ; 57,0$ e 59,6 dos anos analisados, inclusive há valores zero.

Os desvios relativos dos totais de chuvas observados nos anos de El Niño e La Niña de intensidades forte, em milímetros e em percentagem, determinados em relação às medianas esperadas pelas Equações 1 e 2 e comparados com os desvios padrão da média (DP $\uparrow \mathrm{e} \downarrow$ ) são mostrados nas Figuras 4 e 5.

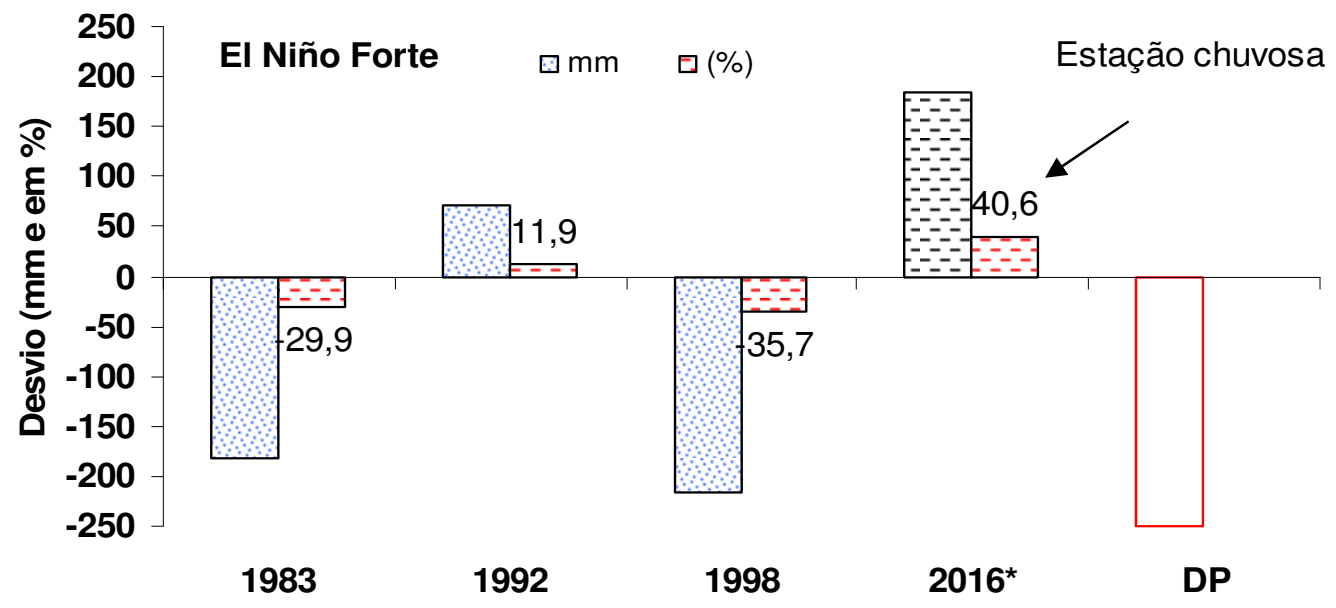

Figura 4. Desvios relativos da chuva nos anos de El Niño de intensidade forte comparados com o desvio padrão da média (DP). Médias para as messorregiões paraibanas do Sertão e Borborema.

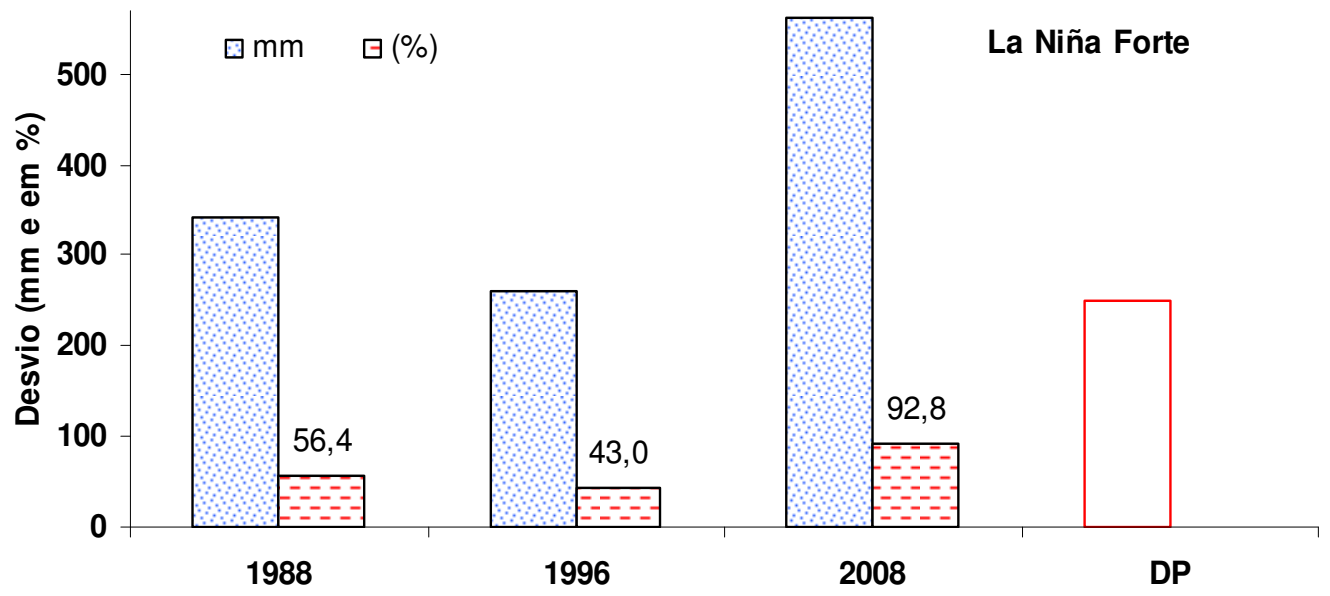

Figura 5. Desvios relativos da chuva nos anos de La Niña de intensidade forte comparados com o desvio padrão da média (DP). Médias para as messorregiões paraibanas do Sertão e Borborema.

Observa-se (Figura 4) que nos três anos de ocorrência do El Niño, dois tiveram desvios negativos, ou seja, chuvas abaixo da media, o ano 1992 acima e a estação chuvosa de 2016. Nos anos com La Niña de intensidades fortes (Figura 5), todas as chuvas foram acima da mediana esperada.

É importante destacar que, ao comparar os totais de chuvas observados nos anos de El Niño, com o desvio padrão da série (esperado), mesmo com desvios relativos negativos em 1983 e 1998 (Figura 4), foram menores que o DP e equivale, em média, a cerca de 79,0 \% do desvio padrão da média. Mesmo chovendo menos não há como creditar que a causa única seja o El Niño.

O mesmo raciocínio pode ser aplicado aos anos de La Niña (Figura 5), cujos desvios foram positivos, ou seja, chuva acima da mediana esperada. Nota-se, também, que os desvios da chuva observados, no acumulado anual, foram superiores ao próprio desvio padrão. No entanto, a elevada dispersão espacial ou temporal no regime pluvial local, intra micro ou mesorregional pode "mascarar" se os desvios positivos provêm exclusivamente do La Niña de intensidade forte.

Nos eventos analisados, destacam-se os anos de 1992, de El Niño de intensidade forte (Figura 4), por ter chovido acima do esperado, e o de La Niña de intensidade forte de 2008 (Figura 5 ), por ter chovido quase o dobro do esperado.

As oscilações no regime de chuvas no semiárido nordestino e, em particular, no território paraibano, tanto quanto ao acumulado anual quanto à distribuição mensal e na estação 
chuvosa, como, por exemplo, a de 2016, não parece ser uma exclusividade do El Niño, mesmo nos anos com intensidade forte.

Analogias semelhantes aos anos de ENOS de intensidade forte, foram feitas para o extremo mínimo (fraca). As Figuras 6 e 7 mostram,

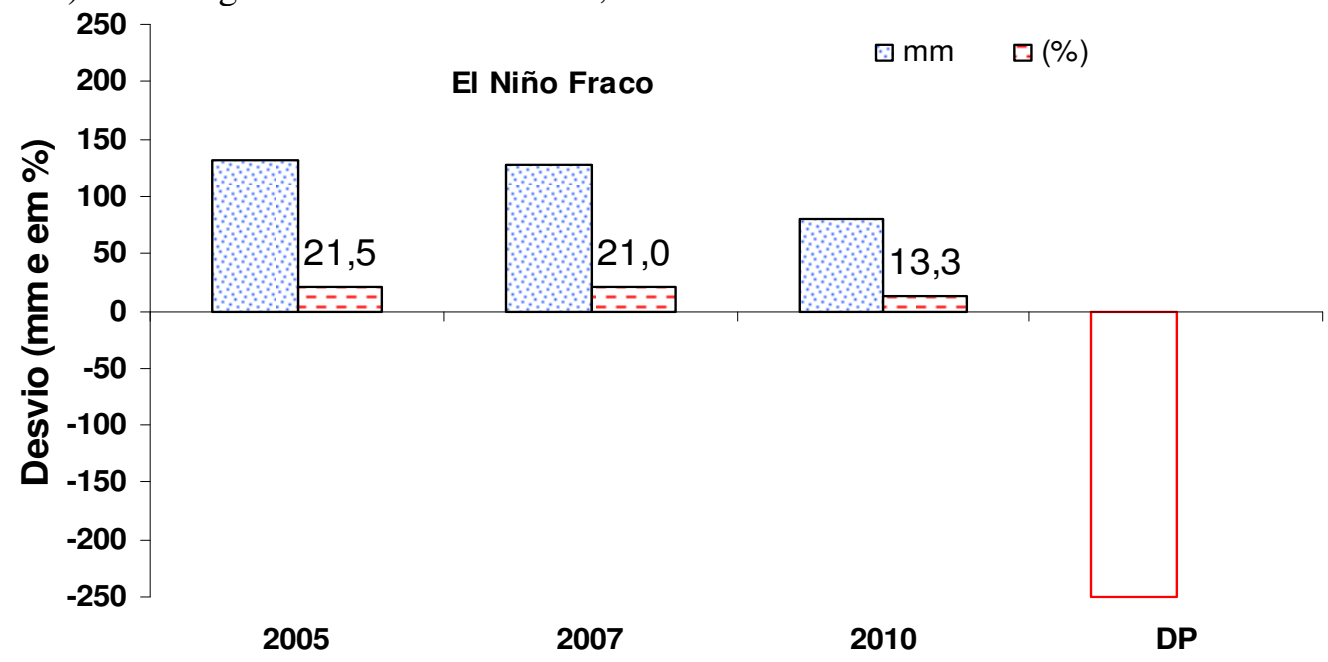

Figura 6. Desvios da chuva nos anos de El Niño de intensidade fraca comparados com o desvio padrão da média (DP). Médias para as messorregiões paraibanas do Sertão e Borborema.

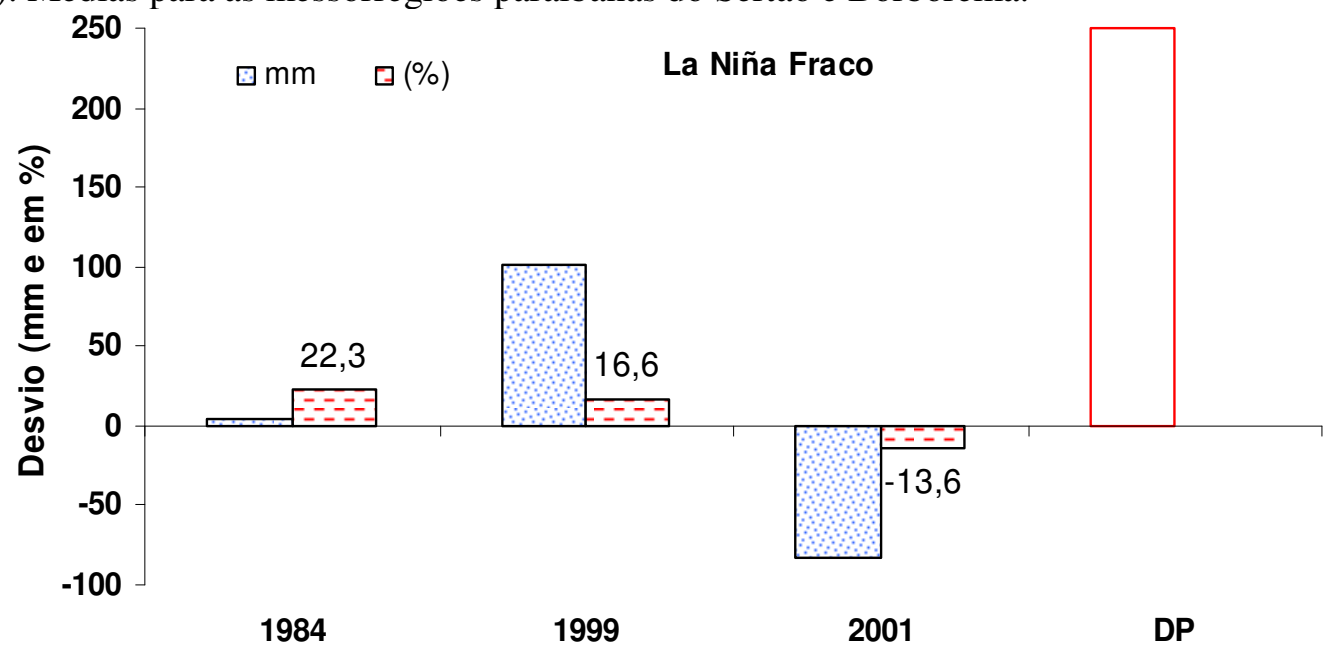

Figura 7. Desvios da chuva nos anos de La Niña de intensidade fraca comparados com o desvio padrão da média (DP). Médias para as messorregiões paraibanas do Sertão e Borborema.

Embora se espere que em ano de EL Niño chova abaixo da mediana (esperada) e no de La Niña, os desvios relativos dos totais de chuvas observados (Figuras 6 e 7 ) não mostraram, respectivamente, essa expectativa. Pelo contrário, nos três eventos El Niño de intensidade fraca choveram acima do valor esperado. Em um ano com La Niña (2001), choveu $14 \%$ a menos.

Constata-se, entretanto, que nas duas fases do ENOS de intensidade fraca, não houvera uma relação efetiva ou exclusiva no quantitativo de chuva, por que o acumulado anual nem sempre foi menor no ano El Niño ou maior no de La Niña

Comparando-se os anos de El Niño e de La Niña de intensidade forte (Figuras 3 e 4) com os de intensidade fraca (Figuras 5 e 6 ), os valores das anomalias negativa e positiva diferem entre si. respectivamente, os desvios relativos dos totais de chuvas observados nos anos de El Niño e La Niña de intensidade fraca, em milímetros e em percentagem, comparados com os desvios padrão da média (DP $\uparrow \mathrm{e} \downarrow$ ).

$$
\square \mathrm{mm} \quad \square(\%)
$$


A Figura 8 apresenta os desvios relativos dos totais de chuvas observados nos anos neutros, comparados com os desvios padrão (DP), da forma especificada no parágrafo anterior.

Observa-se (Figura 8) que mesmos nos anos neutros, nem sempre coincidem com chuvas acima do valor esperado. O ano de 2012, por exemplo, choveu, em média, o equivalente, a cerca de $65 \%$ do esperado, ou seja, $200 \mathrm{~mm}$ a menos.

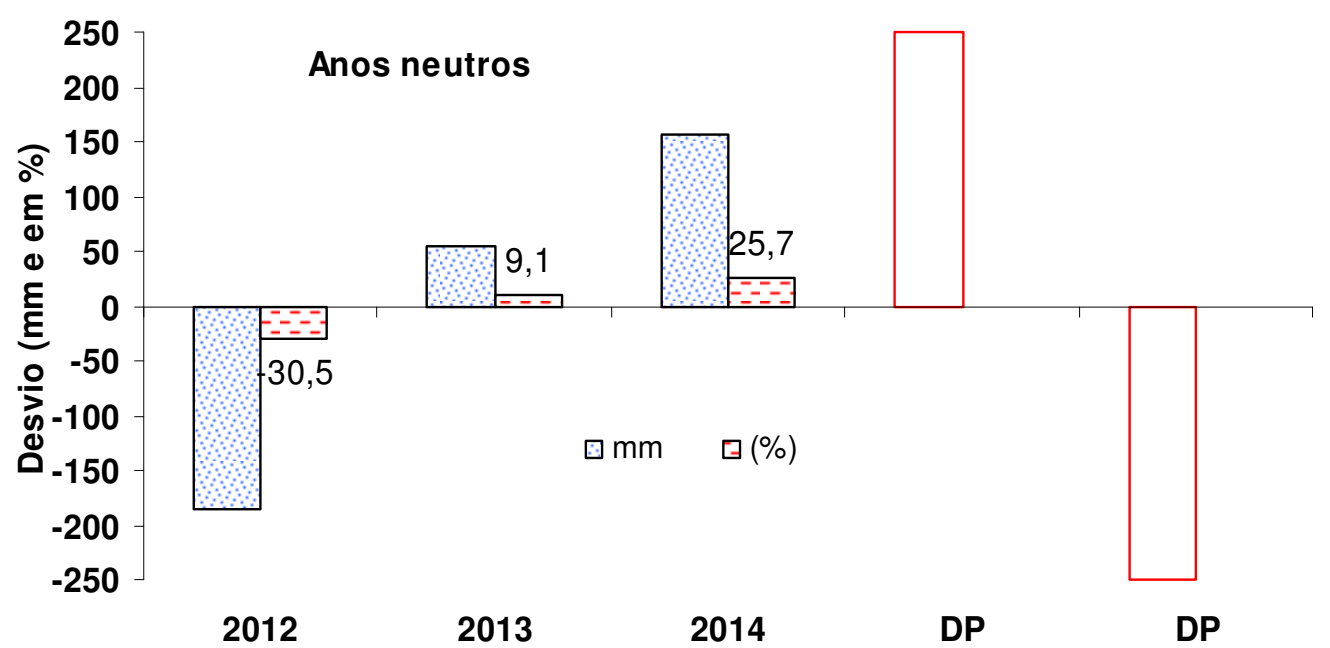

Figura 8. Desvios da chuva nos anos neutros (sem ENOS) comparados com os comparados com \pm o desviopadrão da média (retângulos vermelhos). Médias para as messorregiões paraibanas do Sertão e Borborema.

Embora o desvio anual de 2013 tenha sido positivo, o valor foi irrisório (choveu apenas 55 mm a mais). No entanto, na estação chuvosa, quando o total esperado é de cerca de $66 \%$ do anual, choveu $118 \mathrm{~mm}$ a menos, ou seja, um desvio negativo por volta de $40 \%$, déficit esse muito expressivo.

Comparando-se os desvios negativos da precipitação pluvial apresentados nas Figuras 3 a 8 constam-se que eles existiram, principalmente, nos anos de El Niño de intensidade forte, nos de La Niña fraco e nos neutros.

Em síntese, os desvios médios de chuva observados nos anos de ENOS de intensidade fortes, foram de $60 \mathrm{~mm}$ a menos, nos de El Niño e $300 \mathrm{~mm}$ a mais, nos de La Niña. Nos anos de intensidade fraca, choveu, em média, cerca de 120 mm a mais nos anos de El Niño e não houve diferença nos de La Niña, quando comparado com a mediana esperada.

Destaca-se, ainda, que as oscilações nos totais de chuvas observados nos anos de ENOS ou na ausência dele podem estar associadas à presença, ausência ou perturbação na zona de convergência intertropical (ITCZ), por ser ela a principal indutora de chuvas nas regiões norte e na parte setentrional do nordeste brasileiro.

Anos com anomalia de temperatura da água do oceano do atlântico tropical, particularmente, a leste, contribui com o posicionamento da ITCZ. Essa condição pode contribuir de forma positiva ou negativa no regime pluvial do semiárido nordestino.

O deslocamento da ITCZ mais para o Norte, anos de 2012 e 2013, pode explicar não somente as irregularidades na quantidade mensal (baixa) e na distribuição na estação chuvosa, em especial, por que não houvera o El Niño ou La Niña.

Neste contexto, não há como desprezar o efeito do oceano atlântico, por exemplo, no que se refere ao da anomalia de temperatura superficial das águas, ou seja, do fenômeno denominado dipolo do atlântico. Associando-se com o ENOS, pode ter uma contribuição não somente no quantitativo de chuva, mas na irregularidade na distribuição espacial e temporal.

\section{Discussão}

Em virtude dessa assimetria, recomendase o uso da mediana, em vez da média, o que corrobora com os resultados encontrados para outras localidades por Oliveira, Nóbrega \& Almeida (2012), Almeida \& Cabral Júnior (2014) e Almeida \& Farias (2015).

Esses resultados concordam de forma parcial com os encontrados por Lucena et al. (2011), ao afirmarem que eventos extremos no oceano pacifico tropical influenciam no volume de chuvas na região do Nordeste brasileiro, mas não de maneira igual e direta. 
Resultados semelhantes foram encontrados por Almeida (2002), para nove localidades do sudeste da Bahia, onde o El Niño apresentou influência diferenciada conforme a fase do evento, com totais de chuvas abaixo da média esperada em cerca de $64,0 \%$ dos anos de ocorrência do El Niño. No entanto, anos com chuvas acima ou abaixo da média coincidiram também com os de ocorrência do El Niño como também, na ausência dele.

Esses argumentos convergem com as afirmações de Kane (2001), o efeito do El Niño no Nordeste Brasileiro só responde por cerca de $40 \%$ das chuvas, porque as condições do Atlântico (do dipolo) são extremamente influenciadoras.

Essa analogia corrobora com que a variabilidade no regime pluvial da mesorregião estudada esteja associada à ITCZ, o que concorda com a de Nobre \& Molion (1988), inclusive nos anos mais chuvosos, advenha de um intenso aumento da convergência, como cita Uvo (1989).

\section{Conclusão}

O regime pluvial é irregular e assimétrico e, por isso, recomenda-se o uso da mediana, em vez da média. A curta estação chuvosa perdura por quatro meses (de janeiro a abril) e chove mais da metade do total anual, mas há chances de não chover.

Nos anos de El Niño e La Niña de intensidades fortes, há tendência de chover abaixo e acima do esperado, embora os desvios observados tendam a ser menores, em média, que o desvio padrão da série.

Nos anos de ENOS de intensidade fraca, tende a chover mais nos de El Niño e não há quase redução nos de La Niña. Os anos mais secos ou os mais chuvosos nem sempre coincidem com a ocorrência do fenômeno ENOS. Em anos neutros (sem ENOS) chegam a chover muito menos do que nos de El Niño de intensidade forte.

\section{Referências}

ALMEIDA, H. A. DE; FARIAS, M. P. 2015. Potential for rainwater catchment's as an alternative for human consumption in drier microregion of the state of Paraiba, Brazil. International Journal of Research in Geography, v.1, n.2, p.3237.

ALMEIDA, H. A, DE; CABRAL JUNIOR, J. B. 2014. Variabilidades sazonais e interdecadais da chuva nas microrregiões geográficas do estado da Paraíba. Revista Brasileira de Geografia Física, v.7, n.5 (Núm. Especial-VIWMCRHPE), p.846858 .
ALMEIDA, H. A. DE. 2012. Climate, water and sustainable development in the semi-arid of northeastern Brazil. In: BILIBIO, C.; HENSEL, O.; SELBACH, J. F. (Org.). Sustainable water management in the tropics and subtropics and case studies in Brazil, Unikaseel, Alemanha, v.3, p.271-298.

ALMEIDA, H. A. DE. 2002. Relação entre o fenômeno El Niño-Oscilação Sul e a ocorrência de chuvas no Sudeste da Bahia. Ilhéus, CEPLAC/CEPEC. Boletim Técnico CEPEC, $\mathrm{n}$. 183, 22p.

ALVES, J. M. B.; REPELLI, C. A. 1992. Variabilidade pluviométrica no setor norte do Nordeste e os eventos El-Niño Oscilação Sul. Revista Brasileira de Meteorologia, v.7, n.2, p.583-592.

ANDREOLI, R. V.; KAYANO, M. T. 2007. A importância relativa do Atlântico tropical sul e Pacífico leste na variabilidade de precipitação do Nordeste do Brasil. Revista Brasileira de Meteorologia, v.22, n.1, p.63-74.

BERLATO, M. A.; FONTANA, D. C. 2003. El Niño e La Niña: Impactos no clima, na vegetação e na agricultura do Rio Grande do Sul. Aplicações de previsões climáticas na agricultura. $1^{\mathrm{a}}$ ed. Porto Alegre: Editora da UFRGS.

KANE, R. P. 2001. Limited effectiveness of El Niños in causing droughts in NE Brazil and the prominent role of Atlantic parameters. Revista Brasileira de Geofísica, v.16, n.2, p.231-236.

KANE，R. P. 1989. Relationship between the southern oscillation/El Niño and rainfall in some tropical and midlatitude regions. Proc. Indian Acad. Sci. (Earth Planet Sci.), v.3, p.223-235.

MENDONÇA, F.; DANNI-OLIVEIRA, I. M. 2007. Climatologia: Noções básicas e climas do Brasil. São Paulo: Oficinas e Textos.

MOLION, L. C. B.; BERNARDO, S. O. 2002. Uma revisão da dinâmica das chuvas no Nordeste brasileiro. Revista Brasileira de Meteorologia, v.17, n.1, p.1-10.

NOBRE, C. A.; MOLION, L. C. B. 1988. The Climatology of Droughts and Drought Prediction. In: PARRY, M. P.; CARTER, T. R.; KONIJN, N. T. (eds.), Impacts of Climatic Variations on Agriculture, v.2. Assessments in semi-arid regions D. Reidel Pub. Co. 764p. 
OLIVEIRA, G. C. S.; NÓBREGA, R. S.; ALMEIDA, H. A. DE. 2012. Perfil socioambiental e estimativa do potencial para a captação de água da chuva em Catolé de Casinhas, PE. Revista de Geografia, v.29, n.1, p.75-90.

SOUZA, E. B.; ALVES, J. M. B.; NOBRE, P. 1998. Anomalias de precipitação nos setores norte e leste do nordeste brasileiro em associação aos eventos do padrão de dipolo observados na bacia do atlântico tropical. Revista Brasileira de Meteorologia, v.13, n.2, p.45-55.

TRENBERTH, K. E. 1997. The definition of El Niño. Bulletin of American Meteorological Society, v.78, n.12, p.2771-2777.

UVO, C. R. B. 1989. A zona de convergência intertropical (ZCIT) e sua relação com a precipitação na região norte e nordeste brasileiro. Dissertação de Mestrado. INPE. São José dos Campos. 99p. 